\title{
Michelangelo, ocular bulb, retina and the Creator
}

\author{
Michelangelo, bulbo ocular, retina e o Criador
}

We are reporting on the recent description published ${ }^{1}$ in this journal that describes the interesting perspective for previous descriptions ${ }^{2}$ of the fresco Creation of the Sun, Moon and Plants of the Michelangelo Bounarroti (1475-1564). However, we have a slightly different perspective, in relation to the optic nerves.

According to this description ${ }^{1}$, the nerves would be represented by the heels/feet of the Creator. In our understanding, the heels/feet would be the retina forming part of the ocular bulb (Figure), because when the execution of the fresco, it was already known the relationship between the optic nerve and the ocular bulb².

Besides these anatomical similarities, we can say that both the foot sole somatosensation as visual sensory feedback networks plays a critical role among the active feedback loops that contribute to the control of standing and walking ${ }^{3,4}$.
Of course, at the time of the Michelangelo there was still no proper knowledge of neuronal interactions currently recognized between somatosensory systems, visual, vestibular, numerous brain regions, and the musculoskeletal ${ }^{5}$.

However, we infer that Michelangelo, being a student of Anatomy and Physiology, already knew that the function of heels/feet on the perception of the environment is very similar to the perceptual function of the retina; and this may indeed have influenced Michelangelo in creating this fresco. In addition, the fresco own name: Creation of the Sun, Moon and Plants in the report is words like sun = light that is perceived and processed by the retina.

Tais Malysz ${ }^{1,2}$, Geraldo Pereira Jotz ${ }^{1}$, Guilherme Reghelin Goulart ${ }^{3}$, Deivis de Campos $^{3,4}$
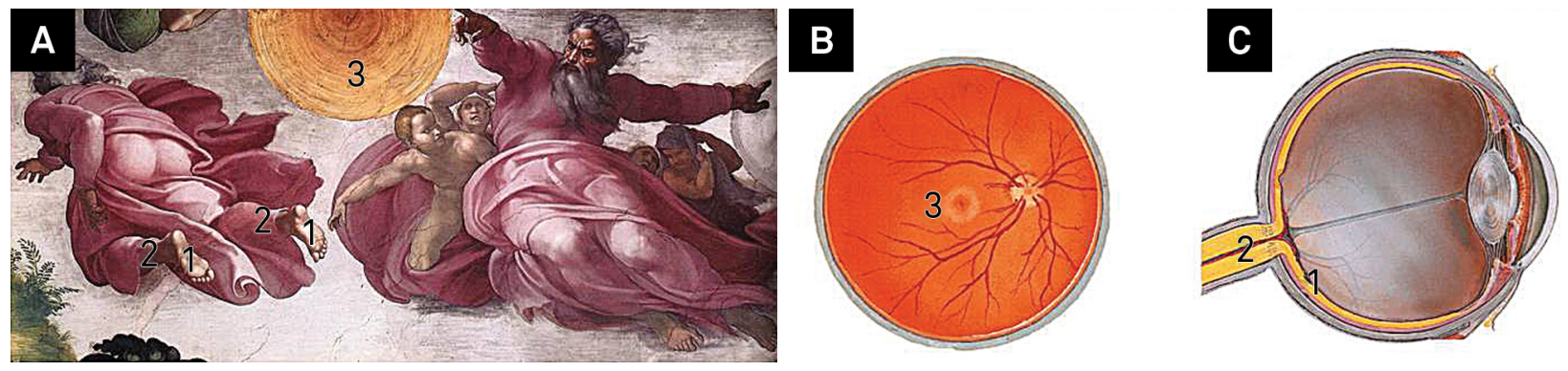

Figure. (A) Detail of Michelangelo fresco (1511): "Creation of the Sun, Moon and Plants" - Heels (1); Legs (2); Sun (3) (Barreto and Oliveira, 2004); (B) Note the similarity between the Sun of the fresco and the retina (3); (C) Drawing showing the ocular bulb/retina (1) connection to the optic nerve (2) (Netter, FH. Atlas of Human Anatomy. $4^{\text {th }}$ Ed. Philadelphia, Saunders, 2006).

\section{References}

1. Maranhão-Filho P, Vincent MB. Michelangelo, mammillary bodies and the Creator. Arq Neuropsiquiatr. 2015;73(2):175. doi:10.1590/0004-282X20140203

2. Barreto G, Oliveira MG. Uma lição de anatomia na Capela Sistina. São Paulo:ARX; 2004. p. 78-9

3. Giagazoglou P, Amiridis IG, Zafeiridis A, Thimara M, Kouvelioti $\mathrm{V}$, Kellis E. Static balance control and lower limb strength in blind and sighted women. Eur J Appl Physiol. 2009;107(5):571-9. doi:10.1007/s00421-009-1163-x
4. Hao Y, Manor B, Liu J, Zhang K, Chai Y, Lipsitz L et al. A novel MRI-compatible tactile stimulator for cortical mapping of foot sole pressure stimuli with fMRI. Magn Reson Med. 2013;69(4):1194-9. doi:10.1002/mrm.24330

5. Manor B, Costa MD, Hu K, Newton E, Starobinets O, Kang $\mathrm{HG}$ et al. Physiological complexity and system adaptability: evidence from postural control dynamics of older adults. J Appl Physiol. 2010;109(6):1786-91. doi:10.1152/japplphysiol.00390.2010

\footnotetext{
${ }^{1}$ Universidade Federal do Rio Grande do Sul, Departamento de Ciências Morfológicas, Instituto de Ciências Básicas da Saúde, Porto Alegre RS, Brazil; Universidade Federal de Goiás, Laboratório de Anatomia Humana e Comparada, Regional Jataí, Jataí GO, Brazil;

${ }^{3}$ Universidade de Santa Cruz do Sul, Departamento de Biologia e Farmácia, Santa Cruz do Sul RS, Brazil;

«Universidade Federal de Ciências da Saúde de Porto Alegre, Departamento de Ciências Básicas da Saúde, Porto Alegre RS, Brazil.

Correspondence: Deivis de Campos; Departamento de Ciências Básicas da Saúde, Laboratório de Anatomia Humana, UFCSPA; Avenida Sarmento Leite, 245; 90050-170 Porto Alegre RS, Brasil; E-mail:dcampos@ufcspa.edu.br

Conflict of interest: There is no conflict of interest to declare.

Received 18 April 2015; Received in final form 30 April 2015; Accepted 19 May 2015.
} 